Chapman University

Chapman University Digital Commons

$9-1-2013$

\title{
Age-Independent Increases in Male Salivary Testosterone During Horticultural Activity Among Tsimane Forager-Farmers
}

\author{
Benjamin C. Trumble \\ University of California, Santa Barbara \\ Daniel K. Cummings \\ University of New Mexico \\ Kathleen A. O'Connor \\ University of Washington \\ Darryl J. Holman \\ University of Washington \\ Eric A. Smith \\ University of Washington \\ See next page for additional authors \\ Follow this and additional works at: https://digitalcommons.chapman.edu/esi_pubs \\ Part of the Biological and Physical Anthropology Commons, Economic Theory Commons, Ethnic \\ Studies Commons, Latin American Studies Commons, Other Anthropology Commons, Other Economics \\ Commons, and the Social and Cultural Anthropology Commons
}

\section{Recommended Citation}

Trumble, B. C., Cummings, D. K., O'Connor, K. A., Holman, D. J., Smith, E. A., Kaplan, H. S., \& Gurven, M. D. (2013). Age-independent increases in male salivary testosterone during horticultural activity among Tsimane forager-farmers. Evolution and Human Behavior, 34(5). https://doi.org/10.1016/ j.evolhumbehav.2013.06.002

This Article is brought to you for free and open access by the Economic Science Institute at Chapman University Digital Commons. It has been accepted for inclusion in ESI Publications by an authorized administrator of Chapman University Digital Commons. For more information, please contact laughtin@chapman.edu. 


\section{Authors}

Benjamin C. Trumble, Daniel K. Cummings, Kathleen A. O'Connor, Darryl J. Holman, Eric A. Smith, Hillard Kaplan, and Michael D. Gurven 


\title{
Age-independent increases in male salivary testosterone during horticultural activity among Tsimane forager-farmers
}

\author{
BENJAMIN C TRUMBLE ${ }^{1}$, DANIEL K CUMMINGS ${ }^{2}$, KATHLEEN A O'CONNOR ${ }^{3,4}$, DARRYL J \\ HOLMAN $^{3,4}$, ERIC A SMITH ${ }^{3,4}$, HILLARD S KAPLAN ${ }^{2}$, and MICHAEL D GURVEN ${ }^{5}$ \\ ${ }^{1}$ Institute for Social, Behavioral, and Economic Research, University of California Santa Barbara \\ ${ }^{2}$ Department of Anthropology, University of New Mexico, Albuquerque \\ ${ }^{3}$ Department of Anthropology, University of Washington, Seattle \\ ${ }^{4}$ Center for Studies in Demography and Ecology, University of Washington, Seattle \\ ${ }^{5}$ Department of Anthropology, University of California Santa Barbara
}

\begin{abstract}
Testosterone plays an important role in mediating male reproductive trade-offs in many vertebrate species, augmenting muscle and influencing behavior necessary for male-male competition and mating-effort. Among humans, testosterone may also play a key role in facilitating male provisioning of offspring as muscular and neuromuscular performance are deeply influenced by acute changes in testosterone. This study examines acute changes in salivary testosterone among 63 Tsimane men ranging in age from 16-80 (mean 38.2) years during one-hour bouts of treechopping while clearing horticultural plots. The Tsimane forager-horticulturalists living in the Bolivian Amazon experience high energy expenditure associated with food production, have high levels of parasites and pathogens, and display significantly lower baseline salivary testosterone than age-matched US males. Mixed-effects models controlling for BMI and time of specimen collection reveal increased salivary testosterone $(p<0.001)$ equivalent to a $48.6 \%$ rise, after one hour of tree chopping. Age had no effect on baseline $(p=0.656)$ or change in testosterone $(p=0.530)$; self-reported illness did not modify testosterone change ( $p=0.488)$. A comparison of these results to the relative change in testosterone during a competitive soccer tournament in the same population reveals larger relative changes in testosterone following resource production (tree chopping), compared to competition (soccer). These findings highlight the importance of moving beyond a unidimensional focus on changes in testosterone and male-male aggression to investigate the importance of testosterone-behavior interactions across additional male fitness-related activities. Acutely increased testosterone during muscularly intensive horticultural food production may facilitate male productivity and provisioning.
\end{abstract}

\section{Keywords}

Challenge hypothesis; testosterone; Tsimane; resource production; competition; physical activity

\footnotetext{
(C) 2013 Elsevier Inc. All rights reserved.

Corresponding Author: Benjamin C. Trumble, PhD, University of California, Santa Barbara, Institute for Social, Behavioral and Economic Research, Santa Barbara, CA 93106, trumble@isber.ucsb.edu.

Publisher's Disclaimer: This is a PDF file of an unedited manuscript that has been accepted for publication. As a service to our customers we are providing this early version of the manuscript. The manuscript will undergo copyediting, typesetting, and review of the resulting proof before it is published in its final citable form. Please note that during the production process errors may be discovered which could affect the content, and all legal disclaimers that apply to the journal pertain.
} 


\section{Introduction}

Testosterone is considered a primary mediating factor in male life history trade-offs, implicated in mate-seeking behaviors, territoriality, and secondary sexual characteristics, at a cost to paternal behavior and maintenance of immune function (Hau, 2007; Wingfield et al., 1990). Consistent with this evolutionary model, human studies find evidence for positive associations between testosterone and various aspects of mating effort including male-male competition (Archer, 2006), aggression (Archer et al., 1998), and attracting mates (Roney et al., 2006), with negative associations between testosterone and parenting effort (Gettler et al., 2011; Muller et al., 2009). The pattern of hormone-behavior interactions resulting in increased testosterone during male-male competition, and decreased testosterone when rearing offspring is commonly discussed under the framework of the "challenge hypothesis" (Archer, 2006; Goymann et al., 2007; Wingfield et al., 1990). The acute portion of the challenge hypothesis, as applied to human males, suggests that testosterone levels are maintained at relatively low levels to avoid the energetic and health costs of high testosterone, but spike when men engage in reproductively important behaviors including male-male competition and sexual activity in order to provide immediate muscular and behavioral advantages (Archer, 2006). While physical confrontations among males provides reproductive access to females in many mammals (Geary, 2000), human males often rely on different behavioral strategies to attract and maintain relationships with mates, tending to focus more on resource production, long-term investment in offspring, and competitive displays than on agonistic male-male interactions (Kaplan et al., 2000b; Pillsworth, 2008; von Rueden et al., 2011).

Resource production is an important predictor of male reproductive success in subsistence and industrialized populations (Borgerhoff-Mulder and Beheim, 2011; Fieder and Huber, 2007; Gurven and Hill, 2009; Gurven and von Rueden, 2006; Hopcroft, 2006; Smith, 2004). Much of male food production involves the use of energy-intensive production techniques to obtain nutritionally dense but hard to acquire food resources, hallmarks of the human feeding niche (Kaplan et al., 2000a). Testosterone promotes muscle growth and maintenance (Bribiescas, 2001), which are not only important in male-male competition, but also vital for physically active food production strategies that would have been the norm throughout most of human evolutionary history.

Although male-male aggression indisputably played a role in human evolution, there are numerous extant, historical, and archaeological examples of social regulations designed to reduce the damage caused by male-male violence, ranging from axe and club fight protocols to state laws (Daly and Wilson, 1988; Hill et al., 2009; Hill and Hurtado, 1996). The coevolution of the human feeding niche, longevity, and brain size may have applied a different set of selective pressures on the role of testosterone in humans, where males who tend to place a greater emphasis on resource production and paternal care than on direct competition when compared to other male mammals (Geary, 2000; Hill et al., 2009; Kaplan et al., 2000a). Increases in male productivity can help maximize reproductive success by improving offspring survivorship, partner fecundity and greater selectivity in the mating market (Kaplan and Hill 1984; Smith 2004; Gurven and Von Rueden 2006). Thus acute increases in testosterone may be one strategy to gain the performance benefits associated with high testosterone, while avoiding the behavioral and immunocompromising effects of high baseline testosterone. This study looks beyond male-male competition to examine changes in testosterone during horticultural activity, and argues for extending the role of testosterone for improving reproductive success by helping to maximize productivity, rather than through traditional male-male competition 
In industrialized populations, male testosterone peaks in the early twenties and declines with age (Harman et al., 2001; Travison et al., 2007a; Uchida et al., 2006). Declines in testosterone among men in industrialized populations have been linked to inflammation, obesity, metabolic disorders, and other age-linked diseases of affluence (Travison et al., 2007a). The Tsimane, and other non-industrialized populations facing energetic constraints and pathogenic stress show lower levels of testosterone across all adult ages as compared with men in industrialized nations, (Bribiescas, 1996; Bribiescas and Hill, 2009; Ellison et al., 2002; Trumble et al., 2012; Vitzthum et al., 2009; Worthman and Konner, 1987), as well a slower and shallower rate of change with age (Ellison et al., 2002), or no association between testosterone and age (Bribiescas, 1996; Trumble et al., 2012; Vitzthum et al., 2009). Male production needs to remain high throughout life in order to provision offspring and grand-offspring; thus, we predict that men in subsistence-based societies, including the Tsimane, will be able to sustain acute increases in testosterone during horticultural activity across the adult life course.

Small-scale slash-and-burn horticulture conducted by Tsimane males offers the opportunity to examine changes in testosterone during tree chopping, a controlled, intense, noncompetitive physical activity. Do Tsimane men express acute changes in testosterone during physical activity similar to the effects of comparable physical activity in industrial populations? Does competitive physical activity produce a greater increase in testosterone than physical activity alone? This study expands the hormone-behavior interaction literature beyond male-male competition and aggression to better understand the importance of acute testosterone-behavior interactions outside of mating-effort, specifically changes in testosterone during tree-chopping for small-scale horticulture.

\subsection{Hypotheses}

Despite having salivary testosterone levels one-third lower than age-matched US males (Trumble et al., 2012), Tsimane men engage in production strategies requiring significant muscle mass and cardiovascular performance. The primary hypothesis of this study is that testosterone will increase significantly during physical activity, despite lower overall levels of testosterone. Exhibiting acute increases in testosterone during physical activity may serve to increase and maintain muscle mass, while still allowing Tsimane men to reap the energetic and immune benefits of low baseline testosterone.

A previous study reported acutely increased testosterone during a soccer tournament among Tsimane men (Trumble et al., 2012). If competition is a main driver of acute changes in testosterone, then we would expect tree chopping to result in a smaller change in testosterone in comparison to the soccer tournament. However, if acute changes in testosterone are largely due to physical activity, then we would expect equivalent changes in testosterone during both activities.

\section{Methods}

\subsection{Participants}

The Tsimane are forager-horticulturalists living in lowland Bolivia. They face higher levels of parasite and pathogen exposure than individuals in the US (Gurven et al., 2009; McDade et al., 2005) as evinced by high levels of C-Reactive protein, erythrocyte sedimentation rates, leukocyte and immunoglobulin levels, and other biomarkers of infection (Gurven et al., 2008; Gurven et al., 2009; McDade et al., 2005; Vasunilashorn et al., 2010). Two-thirds of Tsimane adults present with signs of intestinal parasites, with one-third reporting symptoms of respiratory illness (Gurven et al., 2009). 
In addition to hunting, fishing, and gathering, the Tsimane rely on small-scale horticulture for subsistence, clearing small areas of the jungle to grow staple foods including plantains, sweet manioc, rice, and corn (Reyes-García et al., 2004). When clearing fields, smaller vegetation is first removed with machetes, an activity known as fetsaqui' Then the trees are chopped down (pacan), before burning and planting the field. While women help with harvesting, machete clearing, and planting, the clearing of larger trees is done exclusively by men (Gurven et al., 2009b). Clearing of large trees is arguably the most time-intensive and energy-intensive component of horticulture (Johnson and Johnson, 1975; Kramer, 2005; Madimenos et al., 2011; Wilkie and Curran, 1993). When men chop the largest trees in their plots, they predominantly work alone, with occasional assistance from closely related males. No men in this sample received assistance from unrelated men, nor were any unrelated community members present while participants felled trees. Fields of unrelated men tend to be isolated from each other to avoid potential territorial conflicts; thus men generally cannot see other men or the fields of unrelated men while they are cutting trees. While resource productivity itself can certainly be a form of male-male competition, the secluded nature of tree chopping makes it unlikely that the act of chopping trees itself is inherently competitive.

From July-September 2010, Tsimane men $(n=63)$ aged $16-80$ years participated in a study examining acute changes in salivary testosterone during strenuous physical activity, tree chopping (see Table 1). A subset of men $(n=12)$ were chewing coca leaves during the study; the effects of coca on salivary biomarkers are unknown, thus these individuals were removed from analysis, leaving a total sample size of $n=51$. In August 2010, 82 Tsimane men aged 16-59 participated in a study examining acute changes in testosterone during a soccer game (Trumble et al., 2012) following an identical saliva collection protocol. While these two studies were conducted largely independently, the same researchers collected all specimens in the same villages following the same procedures; fourteen men participated in both studies. Participants were recruited during community meetings, and through word of mouth; our research protocols were approved by the University of Washington Human Subjects Division.

\subsection{Data Collection}

Participants rinsed their mouths with water, and provided their first $1-2 \mathrm{~mL}$ of passive drool saliva 5-15 minutes before beginning to chop trees, and a second specimen after one hour of intensive tree chopping. Following an identical protocol, men participating in soccer tournament provided saliva specimens 15 minutes before and 10 minutes after a competitive soccer match.

All of the men in this sample chopped trees with metal-headed axes, with some men also employing machetes to cut vines or smaller branches from trees to facilitate tree clearing. In this sample, the trees being chopped ranged in size and hardness, though all men recruited were chopping trees $>100 \mathrm{~cm}$ in circumference on the day saliva specimens were collected. The time of initiation of tree chopping ranged from 7:15AM to 3:26 PM, and the soccer games took place between 11:00AM and 1PM. A subset of participants wore Polar RS $800 \mathrm{CX}$ heart rate monitors while chopping $(n=31)$. Saliva specimens were frozen in liquid nitrogen until transferred to dry ice and flown to the University of Washington where they were stored for four months; previous studies report that salivary testosterone is sable for at least three years at $-80^{\circ} \mathrm{C}$ (Granger et al., 2004). There were 10 instances where pre-treechopping saliva was missed, as men had begun chopping trees prior to the arrival of the researchers. The time of initial chopping was known, and it was possible to still collect a saliva specimen one hour after beginning physical activity, leading to 10 cases where the initial pre-chopping sample was missing. 
Height was measured with a modified SECA 214 stadiometer, and weight was measured with a TANITA scale; these measures were combined to calculate Body Mass Index (BMI) in $\mathrm{kg} / \mathrm{m}^{2}$ (see Table 1). At the time of participation, men were asked if they were experiencing any symptoms of pain or illness as a simple assessment of disease state. Nearly three-quarters of participants in the tree chopping study $(n=37)$ reported some type of pain (see Table 2), though symptoms were largely mild as these men were able to chop trees. Their reports of symptoms were sub-categorized as illness $(n=27)$ if they reported fever, cough, diarrhea, or other symptoms of active infection.

A subset of participants ( $n=20$ ) also provided two saliva specimens one hour apart on a day when they were resting. The researchers sat with the men while they talked or engaged in non-physically intensive labor (e.g., mending fishing nets), to ensure that changes in testosterone while tree-chopping were not due to the presence of the researchers. In this subsample, eighty percent of the resting men $(n=16)$ reported some symptom of illness or pain.

\subsection{Laboratory Methods}

Saliva specimens were thawed and centrifuged at 2800 RPM for 20 minutes, and the aqueous layer removed and stored at $-80^{\circ} \mathrm{C}$ until assay. All specimens had gone through two freeze thaw cycles when initially assayed. Saliva specimens exhibiting blood contamination ( $n=4$ specimens) were excluded from analysis (Granger et al., 2004), leaving a total of 90 usable physical activity specimens from 49 individuals, and 38 usable resting specimens from 20 individuals. The ages of two men, and BMI for four men were unknown, and coded as missing for analysis. Salivary testosterone was measured via in-house enzyme immunoassay (Muir et al., 2001; Trumble et al., 2012). All specimens were run in duplicate, and all of the samples collected from each participant were run on the same plate to eliminate inter-plate variation. The within and between assay coefficients of variation for this project ( $n=24$ plates) were $4.49 \%$ and $9.29 \%$ respectively for the low $(403.13 \mathrm{pg} / \mathrm{mL}$ ) and $5.47 \%$ and $11.35 \%$ for the high $(681.37 \mathrm{pg} / \mathrm{mL})$ controls.

\subsection{Statistical Analyses}

All testosterone data were log transformed for analysis to control for non-normality. Maximum likelihood linear mixed-effects models examined the absolute levels of testosterone change after one hour of tree-chopping. Individuals were coded as a random effect to control for the non-independence of repeated measures from each participant (West et al., 2007). Linear regression models examined relative changes in testosterone. Potential covariates (fixed effects) included age (linear, quadratic, and dummy variables), BMI, time of day, symptoms of pain (binary), and symptoms indicative of illness (binary). Analyses were conducted in STATA 12.1 (College Station, TX).

\section{Results}

\subsection{Testosterone and tree chopping}

Prior to chopping trees, the average salivary testosterone level for these men was $201.9 \mathrm{pg} /$ $\mathrm{ml}(\mathrm{SD}=111.9)$; following one hour of tree chopping, the mean testosterone increased to $300.0 \mathrm{pg} / \mathrm{mL}(\mathrm{SD}=143.6)$. Percent change in un-logged testosterone was calculated $(\Delta=$ [Post chopping testosterone - Pre chopping testosterone]/Pre chopping testosterone), indicating a $48.6 \%$ increase in testosterone following one hour of physical activity. The distribution of testosterone change was right skewed, see figure 1, and thus log testosterone was used in all statistical analysis. The most parsimonious linear mixed effects model as determined by likelihood ratio tests indicates that log testosterone increased significantly following an hour of tree chopping $(\beta=0.45, p<0.001)$, controlling for BMI, and time of specimen collection (Table 3 model 1, Figure 2 ). Covariates for age $(p=0.656)$, reporting 
pain ( $p=0.625$ ), and reporting symptoms of illness ( $p=0.488$ ), were not significant (Table 3 , models $2-4$, Figure 3 ). Additional analyses modeling age as quadratic, binary (below median age, above median age), and dummy variables (dividing age into terciles and decades), found no significant impact of age on testosterone levels or change in testosterone (see also Figure 3). Linear regression models also found no association between age and the percent change in testosterone $(p=0.530)$, pain and percent change in testosterone $(p=0.386)$, or illness and percent change in testosterone $(p=0.142)$, controlling for time of specimen collection and BMI. There was no association between testosterone and average heart rate while tree chopping ( $p=0.888$, model 5), controlling for BMI, time of specimen collection, and age.

\subsection{Testosterone and resting}

Separate linear mixed effects models were constructed to examine salivary testosterone collected before and after men rested for one hour (Table 3), to evaluate whether the presence of researchers influenced testosterone. Resting in the presence of researchers had a small and non-significant effect on testosterone $(\beta=-0.09, p=0.244)$, controlling for BMI and time of day, equivalent to a $4.47 \%$ decrease in testosterone. In a separate analysis of the resting sample (not reported in Table 3), there was a trend toward older men reporting more symptoms indicative of pain than younger men $(\beta=.01, p=0.052)$; thus additional models were constructed including age and pain symptoms as covariates. In model 3 (Table 3 ), men reporting symptoms of pain had lower levels of testosterone ( $\beta=-0.47, p=0.047)$.

\subsection{Comparison of testosterone elevations from tree chopping and soccer}

A one-sided two-sample $t$ test with unequal variances (Welsh's approximation) compared the percent increase in testosterone from men cutting trees $(n=47, M=48.6 \%, S E=6.9)$ with the percent increase seen during a soccer game $(n=83, M=30.1 \%, S E=4.1)$, see table 1 (Trumble et al., 2012), finding a significantly larger change in testosterone among men chopping trees $(p=0.008)$. A comparison of distributions of testosterone change can be viewed in figure 1. It should be noted that there were fourteen men who both competed in the soccer tournament and chopped trees; within this subset of men, the percent change in testosterone was higher when chopping trees $(\mathrm{M}=40.6 \%)$ than following a soccer tournament $(\mathrm{M}=36.3 \%)$. A linear mixed effects model comparing the percent change in testosterone controlling for age, BMI, time of specimen collection finds a non-significantly larger increase in testosterone percent change when comparing tree chopping and soccer in the same individuals $(\beta=1.19, p=0.952$ ), though it should be noted that there is insufficient power to conduct this analysis with just $n=14$ participants.

\section{Discussion}

Despite having lower baseline testosterone levels than men in industrialized populations (Trumble et al., 2012), Tsimane men experienced a significant increase (48.6\%) in testosterone following strenuous physical activity, at a magnitude similar to or above levels of change reported in studies of competitive sports in industrialized populations (Archer, 2006). Age had no effect on testosterone or on change in testosterone during physical activity. There was a small non-significant change in testosterone (equivalent to a $4.47 \%$ decrease in testosterone) when a sub-group of men rested in the presence of researchers, indicating that the presence of researchers had no effect on testosterone levels measured in this study.

This study was designed to replicate the sampling framework of a previous study which reported a $30.1 \%$ increase in Tsimane salivary testosterone during a one hour competitive soccer match. A comparison of the relative increase in testosterone during tree chopping and 
soccer finds evidence of significantly larger relative increase in testosterone during tree chopping. To our knowledge this is the first study to compare differences in testosterone change for competitive versus subsistence-based physical activity using the same protocols and following the same analytical methods in the same population.

Acute increases in testosterone during resistance activity benefit muscular metabolism, increasing sugar uptake, and enhancing neuro-muscular performance within minutes (Crewther et al., 2011; Tsai and Sapolsky, 1996). Because men usually chop trees for several hours at a time, relatively rapid increases in testosterone would enhance performance, allowing men to increase their tree chopping efficiency. While studies of resistance training find positive associations between acute changes in testosterone and long term strength gain (Rønnestad et al., 2011), the period of time when men are engaging in tree chopping (pacian) lasts only a few weeks, which is unlikely to be enough time for men to benefit from increases in muscle mass. Additionally, these seasonal periods of intense horticultural work may not generalize to hunter-gatherer subsistence strategies that would have been the norm throughout much of human evolution. That said, the acute benefits of testosterone on muscle performance occur within a matter of minutes (Tsai and Sapolsky, 1996), and could be valuable for a number of physically demanding modes of resource production beyond tree chopping, including activities like animal pursuit during hunting (Trumble et al., In Review). As increased testosterone can entail energetic and immunosuppressive costs (Muehlenbein and Bribiescas, 2005), one would hypothesize that increases in testosterone occur only in situations offering significant benefit to the individual. While many studies have focused on testosterone and aggressive or competitive activities related to mating effort, our results underscore the importance of testosterone in male physical labor and production strategies. Enhanced muscular performance is beneficial in a variety of circumstances and across life history stages; studies of short-term increases in testosterone need not limit themselves to direct male-male physical confrontations in mating-effort contexts.

Mammalian females also exhibit the ability for acute changes in testosterone during physical activity, suggesting that testosterone lability is an ancestral trait in vertebrates (Aizawa et al., 2008). This raises the possibility that rapid muscular enhancement may have been originally advantageous for general muscle productivity and later evolved functional roles in malemale competition. Across taxa, baseline testosterone is a major determining factor in the levels of sexual dimorphism in body size, muscle mass and other sexually discordant somatic features (Bardin and Catterall, 1981; Lassek and Gaulin, 2009). Current and paleoanthropological evidence of sexual dimorphism suggests that male-male competition has played an important role in human evolution, though human sexual dimorphism is much lower than the levels of dimorphism noted in ancestral populations (Plavcan and van Schaik, 1997; Ruff, 2002). Human testosterone and sexual dimorphism could thus have been selected for during periods when male-male conflict played a more important role in male reproductive success. Or perhaps the co-evolution of human brain size and feeding niche led to sexual division of labor that favored physically intensive male production strategies, and therefore an advantage in retaining sexual dimorphism (Gurven et al., 2009b; Kaplan et al., 2000a).

If evolutionary pressures asserted by male-male competition resulted in selection for acute increases in testosterone, then one would predict reduced selective pressure for older men to maintain this ability, as their fertility would already largely be realized by the time their partners reach menopause (Kaplan et al. 2010), and any potential competitive interactions would be occurring in the 'selection shadow' (Kirkwood and Austad, 2000), or at least under reduced selection pressure. If instead, resource production was a major driver of male ability to sustain acute increases in testosterone, we would expect older men to be able to 
sustain acute increases in testosterone, given that older men contribute substantial resources to offspring and grand-offspring (Kaplan et al., 2010) thereby increasing their fitness. We think it likely that selective pressures have favored the capacity for acute increases in testosterone due to physical activity as well as in competitive situations, but argue that relative levels of importance for these two activities may be different among humans as opposed to non-human primates, or other mammals with less paternal involvement.

Our results are similar to those reported by other researchers examining exercise-induced testosterone change in industrialized populations, which find that physical activity (Hackney et al., 1995; Vingren et al., 2010), especially resistance-based activities (Tremblay et al., 2004), result in increased circulating testosterone. Studies in the US find this to be true for both younger and older men (Baker et al., 2006; Hakkinen et al., 2000; Kraemer et al., 1999). Contrary to our findings, which suggest no age-related differences in testosterone response to physical activity, several studies in industrialized populations indicate that the magnitude of testosterone change during some resistance activities is diminished in older men compared to younger men (Baker et al., 2006; Hakkinen et al., 2000; Kraemer et al., 1999; Vingren et al., 2010). The differences between our results and these studies may be related to the higher levels of testosterone reported in industrialized populations, and the age-related differences in testosterone reported in industrialized populations, but not among subsistence populations (Ellison et al., 2002; Trumble et al., 2012). Studies of non-physical competitive activities also report no age-related differences in testosterone change following a dominoes competition (Flinn et al., 2012), and after exposure to sexual stimuli (Escasa et al., 2011).

While many have argued that decreases in testosterone with fatherhood would increase investment in current offspring (Gettler et al., 2011; Gray et al., 2002), in subsistence populations dependents necessitate increased food production, and thus a diminished testosterone response during physical activity could have negative effects on physically intensive food production strategies. Studies of testosterone supplementation show that the muscles of older males are as responsive as young men to physiological effects of testosterone (Bhasin et al., 2005). Thus when older Tsimane men express acute increases in testosterone during physical activity, they are likely to receive the same acute benefits of increased muscle performance as younger men (Crewther et al., 2011; Rønnestad et al., 2011; Tsai and Sapolsky, 1996). That said, it seems unlikely that increases in testosterone are able to offset other age-related physical changes, including decreased visual and auditory acuity and cardiovascular ability, which result in decreased subsistence productivity for older men engaged in hunting (Gurven et al., 2006; Walker et al., 2002), foraging (Walker et al., 2002) and clearing trees for small-scale horticulture (Cummings et al., in prep).

The Tsimane are subsistence-level foragers-horticulturalists living in a parasite- and pathogen-rich environment (Gurven et al., 2009), which is one explanation for why they have lower levels of testosterone than US males (Ellison et al., 2002; Trumble et al., 2012). While low testosterone is advantageous for reducing physiological costs, testosteronemediated muscle mass is important for strength-related food production activities, like clearing forest for planting subsistence crops. If men are able to lower physiological costs by having low testosterone most of the time, but still exhibit acute increases in testosterone during physical activity, they would maximize muscle performance with minimum cost. This pattern is noted in relation to male-male competition across many taxa (Wingfield, 2005; Wingfield et al., 1990). Our results support expanding human applications of the challenge hypothesis to include acute changes in testosterone during non-competitive situations that are associated with increased reproductive success such as subsistence labor. 


\subsection{Limitations}

A major strength of comparing tree-chopping and soccer is that these are ecologically valid forms of physical labor and competition experienced by Tsimane males, as opposed to contrived laboratory tasks. Unfortunately, by examining naturally occurring events under field conditions, we could not control for all potential differences between these groups in the way participants could be monitored in a laboratory. The men participating in the tree chopping and soccer tournament studies were largely separate samples and did vary in age. Mean changes in testosterone for the fourteen men who participated in both studies do follow the expected patterns, and while regression analyses controlling for age, BMI, and time of specimen collection indicate non-significantly larger percent changes in testosterone following tree-chopping, they lack statistical power due to small sample size. Because of the time intensive nature of the data collection, it was not logistically possible to collect treechopping specimens and data from all men who participated in the soccer study. As small scale horticulture is a vital to Tsimane subsistence strategy, and practiced by nearly all men in these communities, there is no a priori reason to believe the samples are intrinsically different. All specimens were run in the same laboratory following the same protocols. To our knowledge, this is the first study to compare changes in testosterone for men participating in competitive and non-competitive physical activities using data collected under ecologically valid conditions.

The chopping of the large trees is generally done by men working alone, or with the help of sons, brothers, or other closely related men. While the resource production that results from a larger field can offer men an opportunity for indirect competition, the harvest is far enough removed from the act of chopping trees (including burning, planting, weeding, and processing the harvest) that there is less reason to expect that tree-chopping itself, with no audience present, is a fundamentally competitive activity.

The disease status assessment was simple, and future work will quantify immune status with greater precision; saliva specimens precluded using serum-based biomarkers of health status. As noted earlier, self-selection is a significant issue in this study; men who were healthy enough to work in their fields are a self-selected group, as are those who chose to rest. The subset of resting men also suffered from a small sample size $(n=20)$.

This study remains agnostic to the endocrine mechanism responsible for acute changes in testosterone. Because salivary testosterone is thought to only represent unbound testosterone the results of the present study can only attest to a subset of circulating testosterone (Granger et al., 2004), and cannot examine altered clearance rates, changes in the portion of free and bound testosterone, or other potential mechanisms for acute increases in testosterone (Flinn et al., 2012). Unfortunately, data on salivary flow rate was not collected, and thus it is not possible to examine any potential role of dehydration on changes in salivary flow rate. However, previous studies examining changes in testosterone among Western populations report similar changes in circulating testosterone, suggesting that our findings are not due simply to changes in hydration status. Both the soccer tournament and tree chopping studies followed identical protocols, so there is no a priori reason to suspect that differences between the soccer and tree chopping results should be due to differential salivary flow rates.

\subsection{Conclusions}

Our results indicate that Tsimane men exhibit significant increases (48.6\%) in testosterone when engaged in intense physical activity typical of horticulturalists. To our knowledge, this is the first study to directly compare differences in testosterone change during competitive and non-competitive physical activity, finding evidence of larger relative changes in 
testosterone following tree chopping (48.6\%), compared to soccer (30.1\%). While many models of male parental investment in industrialized populations predict decreased testosterone with age, as males invest more in current over future offspring, the inability to mount acute increases in testosterone could actually be detrimental during physically active subsistence production. These findings highlight the importance of moving beyond a unidimensional focus on male-male aggression and direct mating effort as the drivers of changes in testosterone, to better understand the reproductive importance of acute testosterone-behavior interactions.

\section{Acknowledgments}

Grant Sponsorship: Partial support for this research came from NICHD R24HD042828 and 5T32HD007543 to the Center for Studies in Demography and Ecology, and NIA R01AG024119-01, R56AG024119-06, R01AG024119-07 to MG and HK.

Special thanks to all the Tsimane men who participated in the study, and to Amanda Guyton, Eleanor Brindle, Alberto Cari, Bacilio Vie, Arnulfo Cari, Vicente Cuata, Meliton Lero, two anonymous reviewers, and the Tsimane Health and Life History Project Staff.

\section{Work Cited}

Aizawa K, Iemitsu M, Otsuki T, Maeda S, Miyauchi T, Mesaki N. Sex differences in steroidogenesis in skeletal muscle following a single bout of exercise in rats. Journal of Applied Physiology. 2008; 104:67-74. [PubMed: 17975125]

Archer J. Testosterone and human aggression: an evaluation of the challenge hypothesis. Neurosci Biobehav Rev. 2006; 30:319-345. [PubMed: 16483890]

Archer J, Birring SS, Wu FCW. The association between testosterone and aggression among young men: Empirical findings and a meta-analysis. Aggressive Behavior. 1998; 24:411-420.

Baker J, Bemben M, Anderson M, Bemben D. Effects of Age on Testosterone Responses To Resistance Exercise and Musculoskeletal Variables in Men. The Journal of Strength \& Conditioning Research. 2006; 20:874-881.

Bardin C, Catterall J. Testosterone: a major determinant of extragenital sexual dimorphism. Science. 1981; 211:1285-1294. [PubMed: 7010603]

Bhasin S, Woodhouse L, Casaburi R, Singh AB, Mac RP, Lee M, Yarasheski KE, Sinha-Hikim I, Dzekov C, Dzekov J, Magliano L, Storer TW. Older men are as responsive as young men to the anabolic effects of graded doses of testosterone on the skeletal muscle. J Clin Endocrinol Metab. 2005; 90:678-688. [PubMed: 15562020]

Borgerhoff-Mulder M, Beheim BA. Understanding the nature of wealth and its effects on human fitness. Philosophical Transactions of the Royal Society B: Biological Sciences. 2011; 366:344 356.

Bribiescas R. Testosterone levels among Ache hunter-gatherer men. Human Nature. 1996; 7:163-188.

Bribiescas RG. Reproductive ecology and life history of the human male. Am J Phys Anthropol Suppl. 2001; 33:148-176.

Bribiescas RG, Hill KR. Circadian variation in salivary testosterone across age classes in Ache Amerindian males of Paraguay. Am J Hum Biol. 2009; 22:216-220. [PubMed: 19957265]

Crewther BT, Cook C, Cardinale M, Weatherby RP, Lowe T. Two emerging concepts for elite athletes: the short-term effects of testosterone and cortisol on the neuromuscular system and the dose- response training role of these endogenous hormones. Sports Med. 2011; 41:103-123. [PubMed: 21244104]

Daly, M.; Wilson, M. Homicide. A. de Gruyter; New York: 1988.

Ellison PT, Bribiescas RG, Bentley GR, Campbell BC, Lipson SF, Panter-Brick C, Hill K. Population variation in age-related decline in male salivary testosterone. Hum Reprod. 2002; 17:3251-3253. [PubMed: 12456632]

Escasa MJ, Casey JF, Gray PB. Salivary testosterone levels in men at a U.S. sex club. Arch Sex Behav. 2011; 40:921-926. [PubMed: 21165688] 
Fieder M, Huber S. The effects of sex and childlessness on the association between status and reproductive output in modern society. Evolution and Human Behavior. 2007; 28:392-398.

Flinn M, Ponzi D, Muehlenbein M. Hormonal Mechanisms for Regulation of Aggression in Human Coalitions. Human Nature. 2012:1-21. [PubMed: 22411184]

Geary DC. Evolution and proximate expression of human paternal investment. Psychol Bull. 2000; 126:55-77. [PubMed: 10668350]

Gettler LT, McDade TW, Feranil AB, Kuzawa CW. Longitudinal evidence that fatherhood decreases testosterone in human males. Proc Natl Acad Sci U S A. 2011; 108:16194-16199. [PubMed: 21911391]

Goymann W, Landys MM, Wingfield JC. Distinguishing seasonal androgen responses from male-male androgen responsiveness-revisiting the Challenge Hypothesis. Horm Behav. 2007; 51:463-476. [PubMed: 17320880]

Granger DA, Shirtcliff EA, Booth A, Kivlighan KT, Schwartz EB. The "trouble" with salivary testosterone. Psychoneuroendocrinology. 2004; 29:1229-1240. [PubMed: 15288702]

Gray PB, Kahlenberg SM, Barrett ES, Lipson SF, Ellison PT. Marriage and fatherhood are associated with lower testosterone in males. Evolution and Human Behavior. 2002; 23:193-201.

Gurven M, Hill K. Why do men hunt? A reevaluation of "man the hunter" and the sexual division of labor. Curr Anthropol. 2009; 50:51-62. discussion 62-74. [PubMed: 19579355]

Gurven M, Kaplan H, Gutierrez M. How long does it take to become a proficient hunter? Implications for the evolution of extended development and long life span. J Hum Evol. 2006; 51:454-470. [PubMed: 16797055]

Gurven M, Kaplan H, Winking J, Finch C, Crimmins EM. Aging and Inflammation in Two Epidemiological Worlds. J Gerontol A Biol Sci Med Sci. 2008; 63:196-199. [PubMed: 18314457]

Gurven M, Kaplan H, Winking J, Rodriguez D, Vasunilashorn S, Kim J, Finch C, Crimmins E. Inflammation and Infection Do Not Promote Arterial Aging and Cardiovascular Disease Risk Factors among Lean Horticulturalists. PLoS ONE. 2009

Gurven M, von Rueden C. Hunting, social status and biological fitness. Soc Biol. 2006; 53:81-99. [PubMed: 21516952]

Gurven M, Winking J, Kaplan H, von Rueden C, McAllister L. A Bioeconomic Approach to Marriage and the Sexual Division of Labor. Human Nature. 2009b; 20:151-183.

Hackney AC, Premo MC, McMurray RG. Influence of aerobic versus anaerobic exercise on the relationship between reproductive hormones in men. J Sports Sci. 1995; 13:305-311. [PubMed: 7474044]

Hakkinen K, Pakarinen A, Kraemer WJ, Newton RU, Alen M. Basal concentrations and acute responses of serum hormones and strength development during heavy resistance training in middle-aged and elderly men and women. J Gerontol A Biol Sci Med Sci. 2000; 55:B95-105. [PubMed: 10737684]

Harman SM, Metter EJ, Tobin JD, Pearson J, Blackman MR. Longitudinal effects of aging on serum total and free testosterone levels in healthy men. Baltimore Longitudinal Study of Aging. J Clin Endocrinol Metab. 2001; 86:724-731. [PubMed: 11158037]

Hau M. Regulation of male traits by testosterone: implications for the evolution of vertebrate life histories. BioEssays. 2007; 29:133-144. [PubMed: 17226801]

Hill K, Barton M, Hurtado AM. The emergence of human uniqueness: Characters underlying behavioral modernity. Evolutionary Anthropology: Issues, News, and Reviews. 2009; 18:187-200.

Hill, K.; Hurtado, AM. Aché life history: the ecology and demography of a foraging people. Aldine de Gruyter; New York: 1996.

Hopcroft RL. Sex, status, and reproductive success in the contemporary United States. Evolution and Human Behavior. 2006; 27:104-120.

Johnson OR, Johnson A. male/female relations and the organization of work in a Machiguenga community1. American Ethnologist. 1975; 2:634-648.

Kaplan H, Gurven M, Winking J, Hooper PL, Stieglitz J. Learning, menopause, and the human adaptive complex. Ann N Y Acad Sci. 2010; 1204:30-42. [PubMed: 20738273] 
Kaplan H, Hill K, Lancaster J, AMH. A theory of human life history evolution: Diet, intelligence, and longevity. Evolutionary Anthropology: Issues, News, and Reviews. 2000a; 9:156-185.

Kaplan H, Hill K, Lancaster J, Hurtado AM. A theory of human life history evolution: Diet, intelligence, and longevity. Evolutionary Anthropology: Issues, News, and Reviews. 2000b; 9:156-185.

Kirkwood TBL, Austad SN. Why do we age? Nature. 2000; 408:233-238. [PubMed: 11089980]

Kraemer WJ, Hakkinen K, Newton RU, Nindl BC, Volek JS, McCormick M, Gotshalk LA, Gordon SE, Fleck SJ, Campbell WW, Putukian M, Evans WJ. Effects of heavy-resistance training on hormonal response patterns in younger vs. older men. J Appl Physiol. 1999; 87:982-992. [PubMed: 10484567]

Kramer, KL. Maya children: helpers at the farm. Harvard Univ. Press; Cambridge, Mass: 2005. [u.a.]

Lassek WD, Gaulin SJC. Costs and benefits of fat-free muscle mass in men: relationship to mating success, dietary requirements, and native immunity. Evolution and Human Behavior. 2009; 30:322-328.

Madimenos FC, Snodgrass JJ, Blackwell AD, Liebert MA, Sugiyama LS. Physical activity in an indigenous Ecuadorian forager-horticulturalist population as measured using accelerometry. American Journal of Human Biology. 2011; 23:488-497. [PubMed: 21538650]

McDade TW, Leonard WR, Burhop J, Reyes-García V, Vadez V, Huanca T, Godoy RA. Predictors of C-reactive protein in Tsimane' 2 to 15 year-olds in lowland Bolivia. American journal of physical anthropology. 2005; 128:906-913. [PubMed: 16118783]

Muehlenbein MP, Bribiescas RG. Testosterone-mediated immune functions and male life histories. Am J Hum Biol. 2005; 17:527-558. [PubMed: 16136532]

Muir C, Spironello-Vella E, Pisani N, deCatanzaro D. Enzyme immunoassay of 17 beta-estradiol, estrone conjugates, and testosterone in urinary and fecal samples from male and female mice. Horm Metab Res. 2001; 33:653-658. [PubMed: 11733867]

Muller MN, Marlowe FW, Bugumba R, Ellison PT. Testosterone and paternal care in East African foragers and pastoralists. Proc Biol Sci. 2009; 276:347-354. [PubMed: 18826936]

Pillsworth EG. Mate preferences among the Shuar of Ecuador: trait rankings and peer evaluations. Evolution and Human Behavior. 2008; 29:256-267.

Plavcan JM, van Schaik CP. Interpreting hominid behavior on the basis of sexual dimorphism. Journal of Human Evolution. 1997; 32:345-374. [PubMed: 9085186]

Reyes-García V, Byron E, Vadez V, Godoy R, Apaza L, Limache EP, Leonard WR, Wilkie D. Measuring Culture as Shared Knowledge: Do Data Collection Formats Matter? Cultural Knowledge of Plant Uses Among Tsimane' Amerindians, Bolivia. Field Methods. 2004; 16:135156.

Roney JR, Hanson KN, Durante KM, Maestripieri D. Reading men's faces: women's mate attractiveness judgments track men's testosterone and interest in infants. Proceedings of the Royal Society B: Biological Sciences. 2006; 273:2169-2175.

Rønnestad B, Nygaard H, Raastad T. Physiological elevation of endogenous hormones results in superior strength training adaptation. European Journal of Applied Physiology. 2011; 111:22492259. [PubMed: 21327794]

Ruff C. Variation in human body size and shape. Annual Review of Anthropology. 2002; 31:211-232.

Smith E. Why do good hunters have higher reproductive success? Human Nature. 2004; 15:343-364.

Travison TG, Araujo AB, O'Donnell AB, Kupelian V, McKinlay JB. A population-level decline in serum testosterone levels in American men. J Clin Endocrinol Metab. 2007a; 92:196-202. [PubMed: 17062768]

Tremblay MS, Copeland JL, Van Helder W. Effect of training status and exercise mode on endogenous steroid hormones in men. Journal of Applied Physiology. 2004; 96:531-539. [PubMed: 14514704]

Trumble B, Cummings D, Von Rueden C, O’Connor K, Smith E, Gurven M, Kaplan H. Physical competition increases testosterone among Amazonian forager-horticulturalists: a test of the 'challenge hypothesis'. Proceedings of the Royal Society B: Biological Sciences. 2012

Trumble, B.; Smith, E.; O'Connor, KA.; Kaplan, H.; Gurven, M. Successful hunting increases testosterone and cortisol in a subsistence population. In Review 
Tsai LW, Sapolsky RM. Rapid stimulatory effects of testosterone upon myotubule metabolism and sugar transport, as assessed by silicon microphysiometry. Aggressive Behav. 1996; 22:357-364.

Uchida A, Bribiescas RG, Ellison PT, Kanamori M, Ando J, Hirose N, Ono Y. Age related variation of salivary testosterone values in healthy Japanese males. The Aging Male. 2006; 9:207-213. [PubMed: 17178556]

Vasunilashorn S, Crimmins EM, Kim JK, Winking J, Gurven M, Kaplan H, Finch CE. Blood lipids, infection, and inflammatory markers in the Tsimane of Bolivia. Am J Hum Biol. 2010; 22:731740. [PubMed: 20721985]

Vingren JL, Kraemer WJ, Ratamess NA, Anderson JM, Volek JS, Maresh CM. Testosterone physiology in resistance exercise and training: the up-stream regulatory elements. Sports medicine (Auckland, NZ). 2010; 40:1037-1053.

Vitzthum VJ, Worthman CM, Beall CM, Thornburg J, Vargas E, Villena M, Soria R, Caceres E, Spielvogel $\mathrm{H}$. Seasonal and circadian variation in salivary testosterone in rural Bolivian men. Am J Hum Biol. 2009; 21:762-768. [PubMed: 19367574]

von Rueden C, Gurven M, Kaplan H. Why do men seek status? Fitness payoffs to dominance and prestige. Proc Biol Sci. 2011

Walker R, Hill K, Kaplan H, McMillan G. Age-dependency in hunting ability among the Ache of Eastern Paraguay. Journal of Human Evolution. 2002; 42:639-657. [PubMed: 12069505]

West, B.; Welch, KB.; Galecki, AT. Linear mixed models: a practical guide using statistical software. Chapman \& Hall/CRC; Boca Raton: 2007.

Wilkie D, Curran B. Historical trends in forager and farmer exchange in the Ituri rain forest of northeastern Zaïre. Human Ecology. 1993; 21:389-417.

Wingfield JC. A continuing saga: the role of testosterone in aggression. Horm Behav. 2005; 48:253255. [PubMed: 15996665]

Wingfield JC, Hegner RE, Dufty J, Alfred M, Ball GF. The "Challenge Hypothesis": Theoretical Implications for Patterns of Testosterone Secretion, Mating Systems, and Breeding Strategies. Am Nat. 1990; 136:829-846.

Worthman C, Konner M. Testosterone levels change with subsistence hunting effort in! Kung San men. Psychoneuroendocrinology. 1987; 12:449-458. [PubMed: 3441583] 


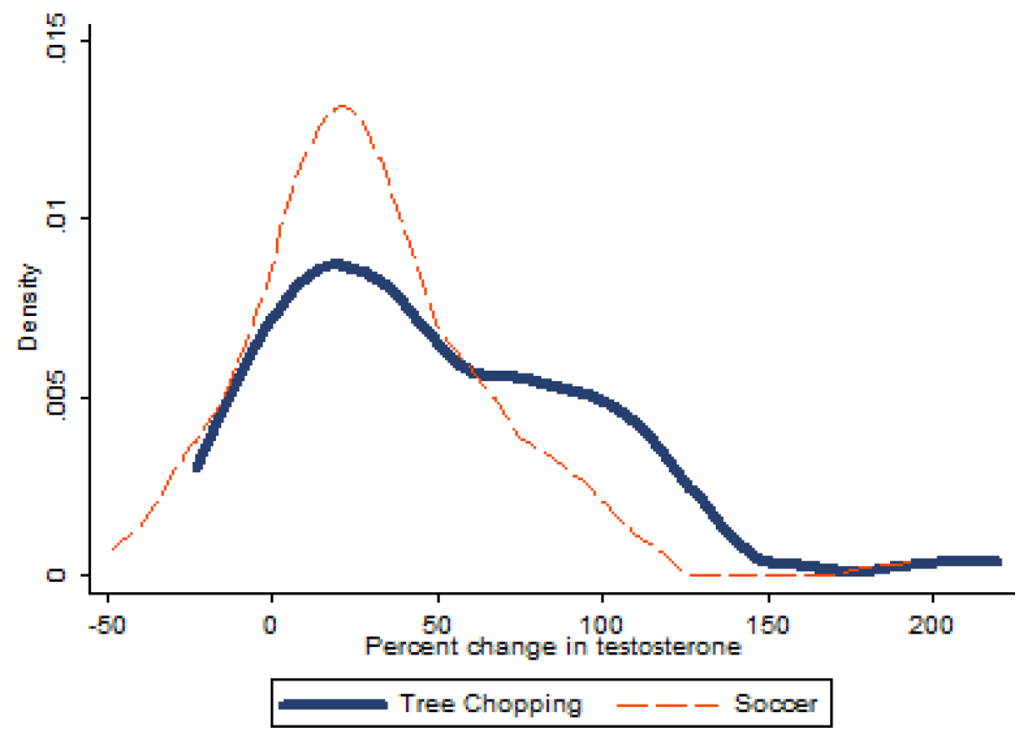

Figure 1.

presents the distributions of percent change in testosterone after one hour of tree chopping $(n=51)$ and one hour of soccer $(n=82)$. 

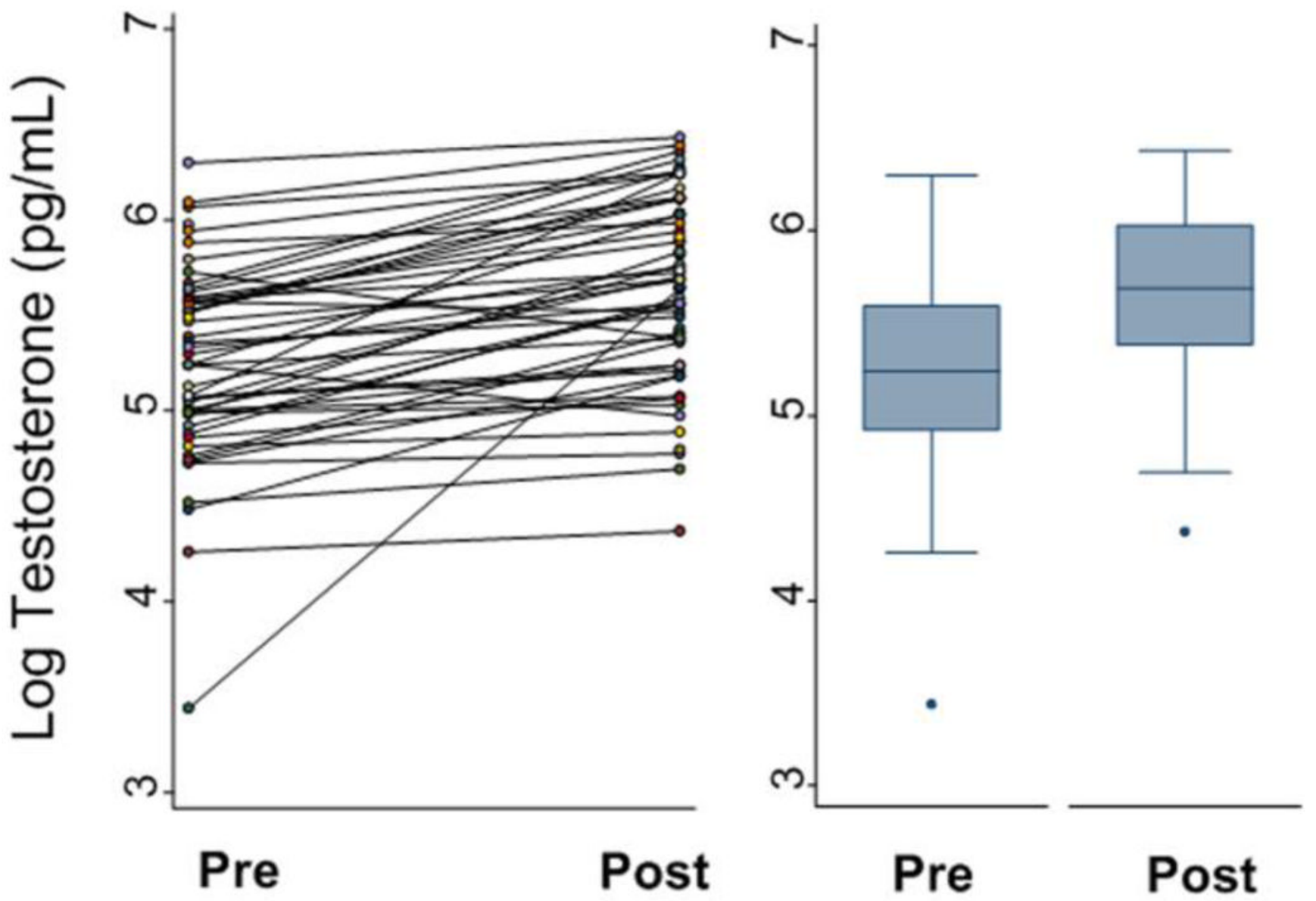

Figure 2. Salivary testosterone before and after one hour of tree-chopping Figure $2 \mathrm{~A}$ represents the individual changes $(n=49)$ in log testosterone before and after intense physical activity. Figure $2 \mathrm{~B}$ is the predicted change in testosterone controlling for BMI, and time of day. 


\section{A: Tree Chopping}

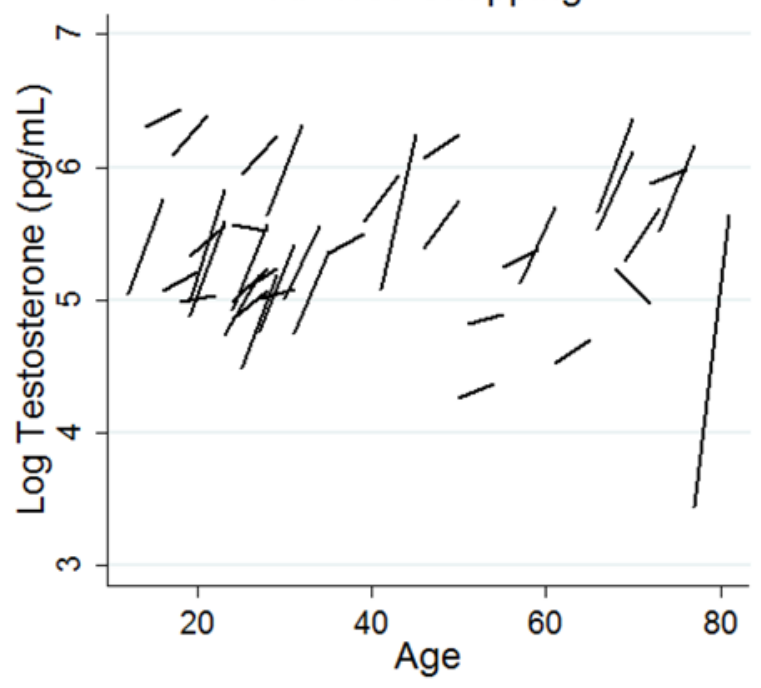

B: Resting

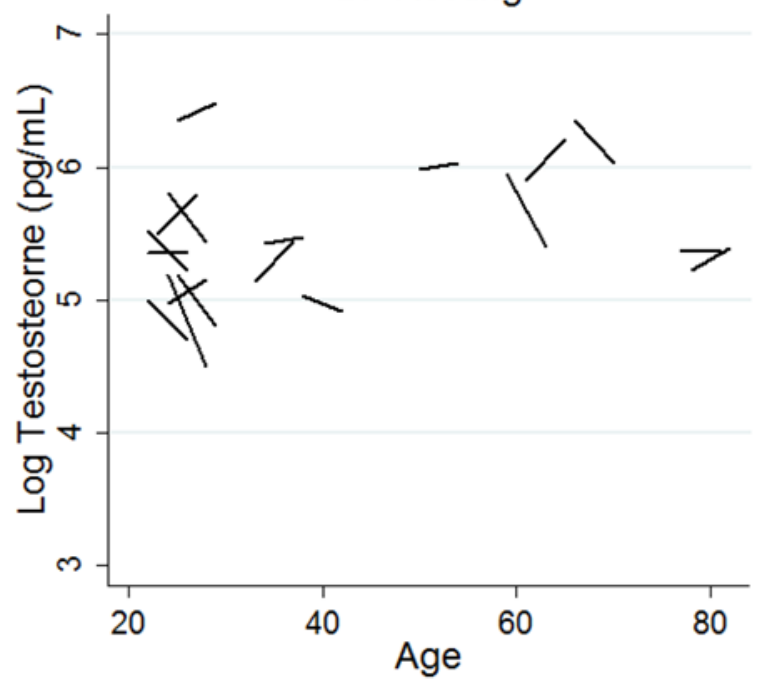

Figure 3. Individual change in testosterone by age for (A) tree chopping and (B) resting Each line segment represents the individual change in testosterone from before to after one hour of (A) tree chopping ( $n=49)$ or $(\mathrm{B})$ resting $(n=20)$ centered on the age of the individual. The left end-point of each line is the testosterone before, and the right end-point represents the individual testosterone after one hour of (A) tree chopping, or (B) resting. 


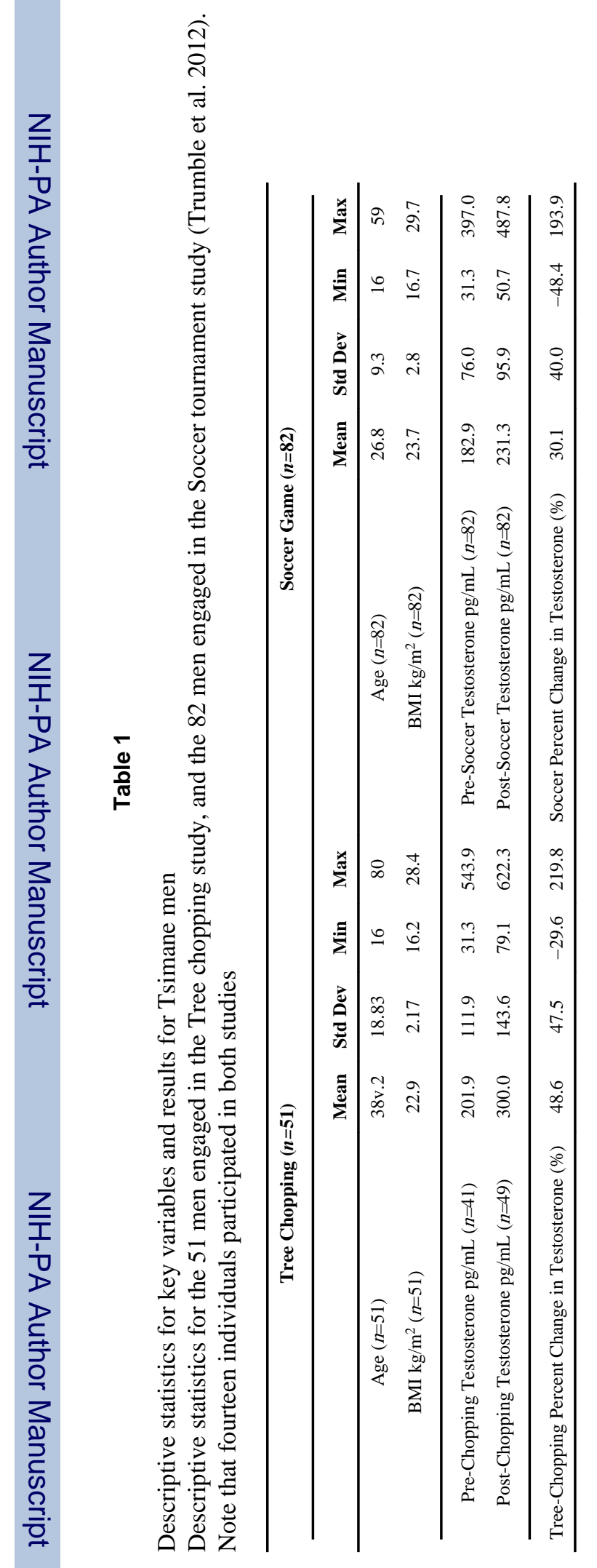




\section{Table 2}

Reports of pain for individuals who were (A) engaged in tree chopping $(n=51)$ or (B) resting $(n=20)$. Responses were then categorized as illness if indicative of infection/parasitism (see text)

\begin{tabular}{|c|c|c|c|c|}
\hline \multicolumn{5}{|c|}{ A: Tree-Chopping } \\
\hline & & \multicolumn{3}{|c|}{ Report Pain } \\
\hline & & No & Yes & Total \\
\hline \multirow[t]{3}{*}{ Illness } & No & 14 & 10 & 24 \\
\hline & Yes & 0 & 27 & 27 \\
\hline & Total & 14 & 37 & 51 \\
\hline \multicolumn{5}{|c|}{ B: Resting } \\
\hline & & \multicolumn{3}{|c|}{ Report Pain } \\
\hline & & No & Yes & Total \\
\hline \multirow[t]{3}{*}{ Illness } & No & 4 & 9 & 13 \\
\hline & Yes & 0 & 7 & 7 \\
\hline & Total & 4 & 16 & 20 \\
\hline
\end{tabular}




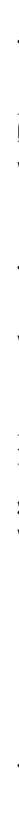

๑ี

bi

$\frac{\overline{2}}{0}$

$\stackrel{\Xi}{\Xi}$

$\mathbb{s}$

$\frac{0}{3}$

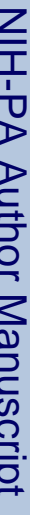

().

5
$\infty$
แี
0

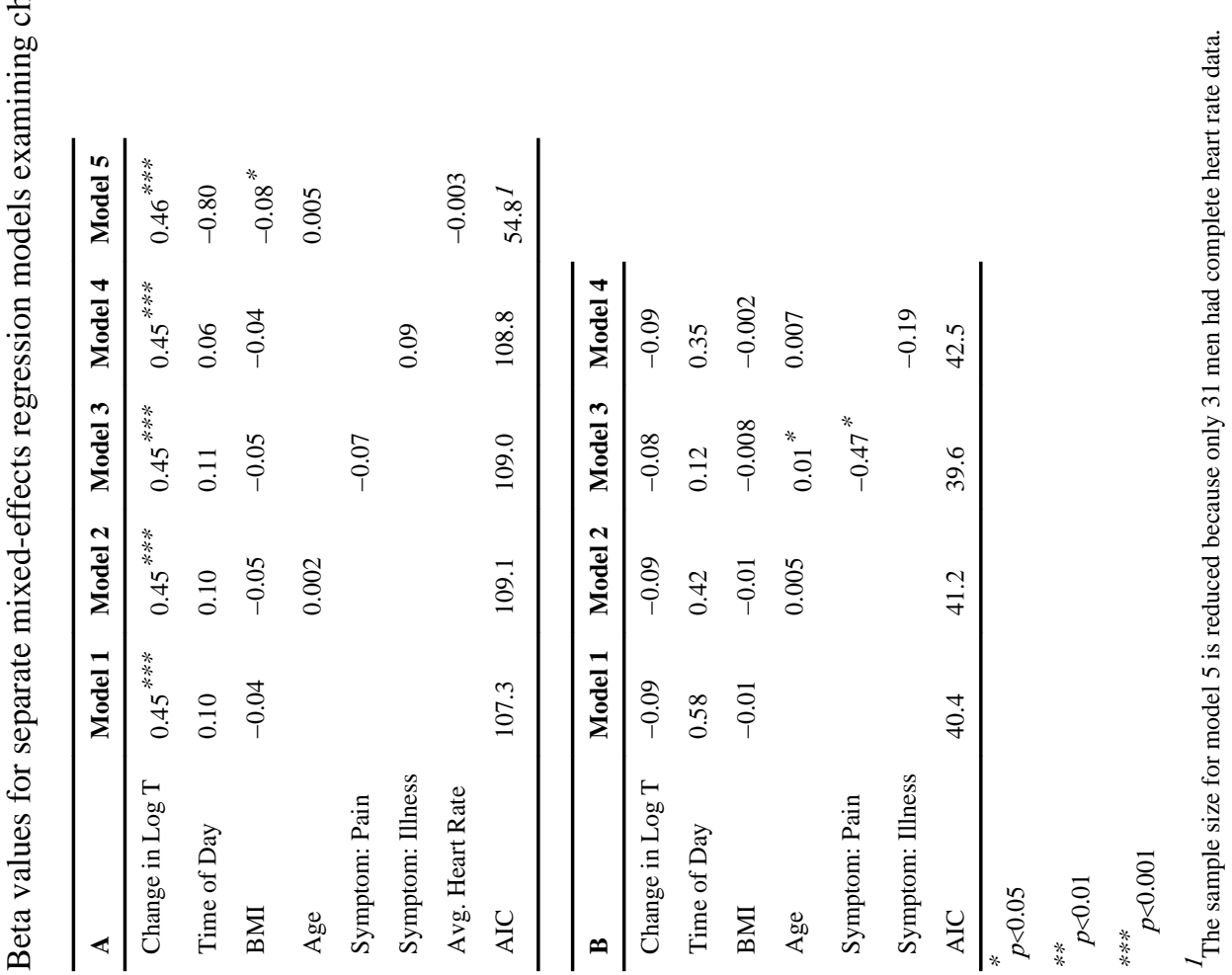

Evol Hum Behav. Author manuscript; available in PMC 2014 September 01. 